\title{
Phylogenetic Relationships of Japanese Unionoida (Mollusca: Bivalvia) Based on Mitochondrial 16S rDNA Sequences
}

\author{
Isao Sano ${ }^{1}$, Akihisa Shirai ${ }^{2}$, Takaki Kondo ${ }^{3}$, Jun-Ichi Miyazaki ${ }^{*}$ \\ ${ }^{1}$ Faculty of Education, University of Yamanashi, Yamanashi, Japan \\ ${ }^{2}$ Musashi High School and Junior High School, Tokyo, Japan \\ ${ }^{3}$ Division of Natural Science, Osaka Kyoiku University, Osaka, Japan \\ Email: *miyazaki@yamanashi.ac.jp
}

How to cite this paper: Sano, I., Shirai, A., Kondo, T. and Miyazaki, J.-I. (2017) Phylogenetic Relationships of Japanese Unionoida (Mollusca: Bivalvia) Based on Mitochondrial 16S rDNA Sequences. Journal of Water Resource and Protection, 9, 493-509. https://doi.org/10.4236/jwarp.2017.95032

Received: March 22, 2017

Accepted: April 27, 2017

Published: April 30, 2017

Copyright () 2017 by authors and Scientific Research Publishing Inc. This work is licensed under the Creative Commons Attribution International License (CC BY 4.0).

http://creativecommons.org/licenses/by/4.0/

\begin{abstract}
Japanese unionoid mussels are classified into 2 families (Margaritiferidae and Unionidae), 12 genera, and 18 species based on the morphological characteristics of both adults and larvae; however, there are some debates regarding their systematics. In this study, we determined mitochondrial $16 \mathrm{~S}$ ribosomal DNA sequences (347-bp) for 60 specimens belonging to 18 species and constructed trees to elucidate phylogenetic relationships and evaluate the current systematics of Japanese unionoid mussels. Almost all species formed clades, except for Inversiunio yanagawensis, Sinanodonta lauta, S. japonica, and Margaritifera laevis, even though two or more specimens were collected from distant localities. All genera formed highly supported clades with the exception of the genus Sinanodonta. Phylogenetic relationships obtained in this study supported systematics based on morphological and larval traits. Therefore, the current phylogenetic relationships and systematics of Japanese unionoid mussels are stronger than they were before; now that they are corroborated by genetic data.
\end{abstract}

\section{Keywords}

Systematics, Molecular Barcoding, Endangered Species,

Conservation, East Asian Mussels

\section{Introduction}

The order Unionoida includes more than 850 species and is more diverse than any other group of freshwater bivalves [1] [2]. Unionoid mussels are widely distributed in all continents except Antarctica and are divided into 6 families (the 
Unionidae, Margaritiferidae, Etheriidae, Hyriidae, Iridinidae, and Mycetopodidae). In Japan, two families, the Unionidae and Margaritiferidae, have been recognized; however, there are some debates regarding the systematics of Japanese unionoid mussels. Kondo [3] classified them into 2 families, 3 subfamilies, 12 genera, 17 species, and 1 subspecies, but later revised his classification [4] to include 2 families, 2 subfamilies, 12 genera, and 18 species (Table 1). In the Unionidae, Kihira et al. [5] included one additional species, Lanceolaria oxyrhyncha (Sasanohagai in Japanese), and founded two subspecies, Nodularia douglasiae biwae (Tateboshigai in Japanese) and $N$. $d$. nipponensis (Ishigai in Japanese), for $N$. douglasiae in Kondo [4] and also two subspecies, Cristaria plicata clessini (Menkarasugai in Japanese) and $C$. p. plicata (Karasugai in Japanese), for $C$. plicata in Kondo [4]. The taxa classified by Kihira et al. are endemic to Lake Biwa

Table 1. Systematics of Japanese Unionoida based mainly on adult morphological characteristics and larval forms [4].

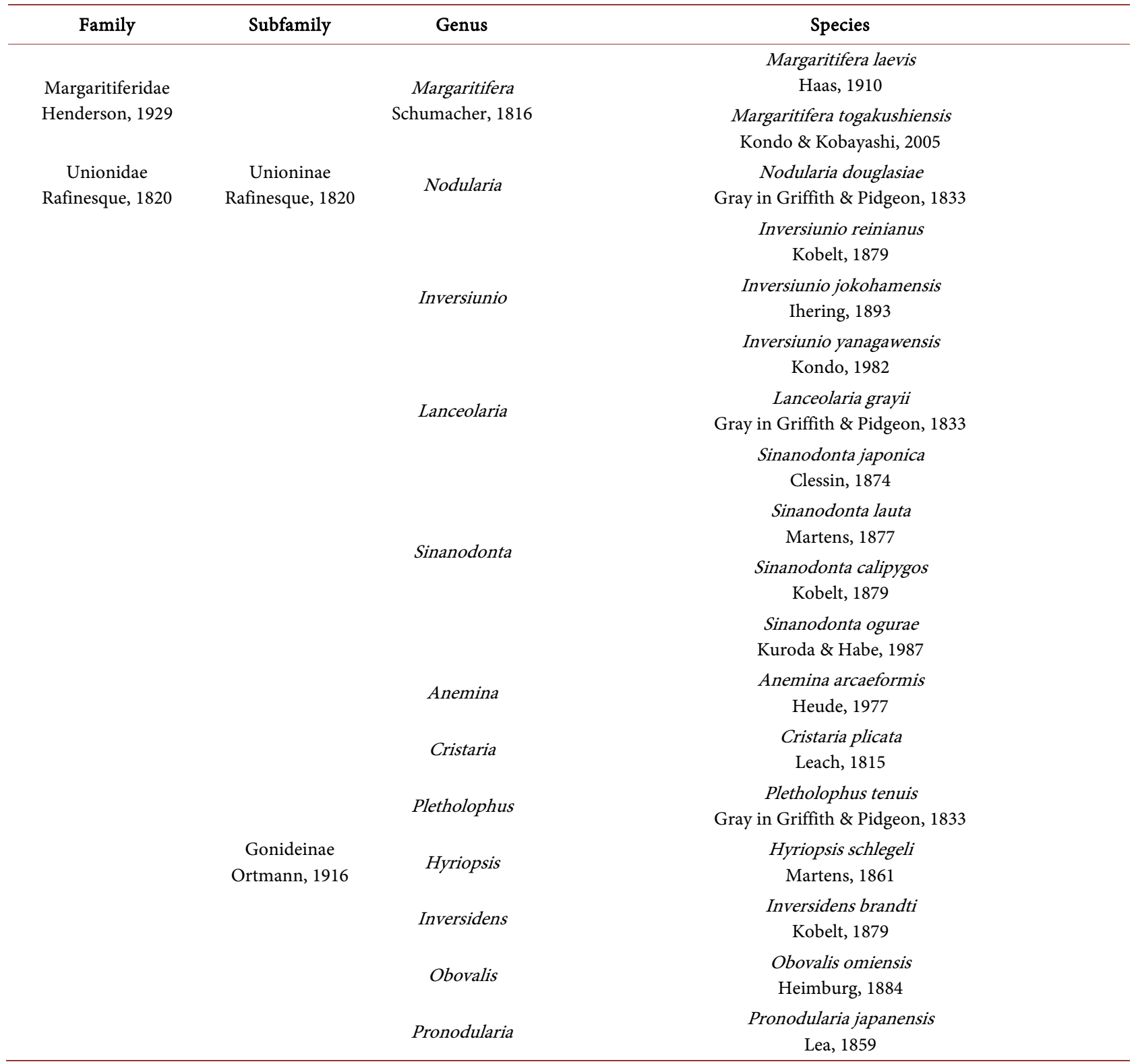


and/or the Yodo River. Although Graf and Cummings [2] reviewed the worldwide unionoids and proposed classification, their classification was still tentative as mentioned by themselves. At present, there is not enough information to deduce relationships between Japanese species and similar species in other parts of the world.

The classification of unionoid mussels has mainly been based on the morphological characteristics of the adults and/or the larvae such as beak sculpture, hinge teeth, shell length and larval hook. Shell characters in particular have attracted a great deal of attention for the classification of unionoid mussels because they can be used to classify fossils. However, Heard et al. [6] suggested that morphological similarities among unionoid species were caused in part by convergent or parallel evolution and not by their ancestry. They also insisted that unionoid systematics based on reproductive aspects more accurately reflected natural, evolutionary affinities than those based on morphological characteristics, and they thus revised the classification of North American unionoid mussels.

Studies using genetic information can objectively provide accurate phylogenetic relationships, reflecting morphological and reproductive differences, and are less influenced by convergent or parallel evolution [7] [8] [9] [10]. Recently, Lopes-Lima et al. [11] investigated the phylogenetic relationships of 70 unionoid species using the mitochondrial cytochrome oxidase subunit I (COI) and nuclear $28 \mathrm{~S}$ rRNA sequences (1032-bp) and showed that unionid mussels formed three clades. They assigned three subfamilies, the Unioninae, Anodontinae, and Gonideinae, to the clades. However, they used only 1 of the 18 Japanese unionoid species identified by Kondo [4]. Takeuchi et al. [12] analyzed the mitochondrial COI and nuclear 18S rRNA and 28S rRNA genes to deduce relationships between the morphologically distinguished Margaritifera togakushiensis and $M$. laevis, and confirmed that $M$. togakushiensis was genetically distinct from $M$. laevis. Their results were further supported from an ecological viewpoint; however, they used only 2 of the 18 Japanese unionoid species. Therefore, the phylogenetic relationships of Japanese Unionoida have not been resolved. To elucidate the phylogenetic relationships of Japanese unionoid mussels, genetic studies using more species are needed.

The Japanese Ministry of the Environment [13] has designated 13 of the 18 Japanese unionoid species as endangered due to deterioration of freshwater systems by human activities [14] [15] [16] [17]. These filter-feeding mussels greatly influence ecological systems and play an important role in purifying water. Negishi et al. [18] unraveled the processes of degradation of unionoid habitats and tried to restore them. Genetic and ecological information is indispensable for preserving wildlife, and one can estimate how long a population is likely to survive by estimating its genetic diversity and population size. Phylogenetic relationships and classification corroborated by genetic analyses are also needed to transplant endangered mussels whose habitats seem to disappear in the near future and to rear them in institutions with genetic contamination avoided.

In this study, we determined mitochondrial 16 S ribosomal DNA sequences 
(347-bp) and constructed trees to elucidate phylogenetic relationships and establish the systematics of Japanese Unionoida. We also constructed trees to reveal relationships of East Asian unionoid mussels using their 16S rDNA sequences (256-bp). We demonstrated that the phylogenetic relationships of Japanese Unionoida obtained in this study supported the systematics proposed by Kondo [4]. Therefore, the phylogenetic relationships and systematics of Japanese unionoid mussels based on genetic and morphological data were in agreement.

\section{Materials and Methods}

\subsection{Materials}

In total, 60 unionoid specimens were collected in Japan and preserved in 99.5\% ethanol. Prior to our genetic study, we identified specimens according to Kondo [4] and assigned them to the Margaritiferidae (2 species) and Unionidae (16 species). However, Nodularia douglasiae was divided into two subspecies, $N$. $d$. biwae and $N . d$. nipponensis, according to Kihira et al. [5], to evaluate the validity of these subspecies. Lopes-Lima et al. [11] reassigned Hyriopsis cumingii to Sinohyriopsis cumingii because this species did not cluster with the other three Hyriopsis species, and Shirai et al. [19] analyzed mitochondrial DNA (COIICOI) and nuclear DNA (ITS1) and showed that $H$. cumingii and $H$. schlegeli were closely related. Therefore, Hyriopsis schlegeli used in this study may be renamed Sinohyriopsis schlegeli in the future. Detailed information about the specimens is listed in Table 2.

\subsection{DNA Sequencing}

We dissected out the foot muscle from each unionoid mussel and boiled them at $100^{\circ} \mathrm{C}$. Then, total DNA was extracted using DNeasy ${ }^{\oplus}$ Blood \& Tissue Kit (QIAGEN GmbH, Hilden, Germany) following the manufacturer's protocol. To amplify the mitochondrial 16S rDNA gene, PCR was performed using KOD dash (Toyobo Co., Ltd., Osaka, Japan) under the following conditions: initial denaturation at $94^{\circ} \mathrm{C}$ for $2 \mathrm{~min}, 40 \mathrm{cycles}$ of denaturation at $94^{\circ} \mathrm{C}$ for $1 \mathrm{~min}$, annealing at $60^{\circ} \mathrm{C}$ for $30 \mathrm{sec}$, and extension at $72^{\circ} \mathrm{C}$ for $1 \mathrm{~min}$, followed by a final extension at $72^{\circ} \mathrm{C}$ for $8 \mathrm{~min}$. We designed the primers (sense 16S-FW1F, 5'-GTTAGCGTGAGCGTGCTAAG-3' and antisense 16S-FW1R, 5'-CGGTCTTAACTCAGCTCGTG-3') to amplify female-type mitochondrial DNA sequences because unionoid mussels have the unique hereditary system named "DUI: doubly uniparental inheritance" [20]. In this system, mitochondria are transmitted from both male and female parents to progeny. The male-type mitochondria, which are highly divergent in DNA sequences from the femaletype mitochondria, are localized exclusively in the testis, whereas the female-type mitochondria are in the whole body except for the testis. When we could not amplify DNA well, we designed two additional antisense primers (16S-FW2R, 5'-TCTTTGGGTCCTTTCGTACAA-3' and 16S-FW3R, 5'-TTGGGGTCCTTTCGTACAA-3') and used them for PCR. PCR products 
Table 2. Specimen details for Japanese unionoids samples used in phylogenetic analyses.

\begin{tabular}{|c|c|c|c|c|c|c|}
\hline$\#$ & Order & Family & Species & Sample Ab. & Locality & Accession No. \\
\hline 1 & Unionoida & Margaritiferidae & Margaritifera laevis & Ma14-1SUTO & Gujo, Gifu, Japan & LC223972 \\
\hline 2 & & & & Ma14-2SUTO & Gujo, Gifu, Japan & LC223973 \\
\hline 3 & & & & Ma14-3SUTO & Gujo, Gifu, Japan & LC223974 \\
\hline 4 & & & & & Iwaizumi, Iwate, Japan & EU590914* \\
\hline 5 & & & Margaritifera togakushiensis & Mt-k & Togakushi, Nagano, Japan & LC224020 \\
\hline 6 & & Unionidae & Nodularia douglasiae biwae & BIWATATE 2 & Lake Biwa, Shiga, Japan & LC223962 \\
\hline 7 & & & & BIWATATE 3 & Lake Biwa, Shiga, Japan & LC223961 \\
\hline 8 & & & & KAWATATE 2 & Lake Kawaguchiko, Yamanashi, Japan & LC223964 \\
\hline 9 & & & & KAWATATE 6 & Lake Kawaguchiko, Yamanashi, Japan & LC223965 \\
\hline 10 & & & & YAMATATE 8 & Lake Yamanakako, Yamanashi, Japan & LC223963 \\
\hline 11 & & & $\begin{array}{l}\text { Nodularia douglasiae } \\
\text { nipponensis }\end{array}$ & Un40-01 & Wakayama, Japan & LC223975 \\
\hline 12 & & & & Un40-02 & Wakayama, Japan & LC223976 \\
\hline 13 & & & & Un43-06f & Nakama, Fukuoka, Japan & LC223977 \\
\hline 14 & & & & Un43-07f & Nakama, Fukuoka, Japan & LC223978 \\
\hline 15 & & & & & South Korea & GQ451850* \\
\hline 16 & & & & & South Korea & GQ451851* \\
\hline 17 & & & & & Jiangxi, China & AF389406* \\
\hline 18 & & & Inversiunio reinianus & Ir07-02 & Lake Biwa, Shiga, Japan & LC223979 \\
\hline 19 & & & Inversiunio jokohamensis & Ij25-01 & Sakai, Yamagata, Japan & LC223980 \\
\hline 20 & & & & Ij25-09 & Sakai, Yamagata, Japan & LC223981 \\
\hline 21 & & & & Ij21-28f & Lake Anenuma, Aomori, Japan & LC223982 \\
\hline 22 & & & & Ij21-30f & Lake Anenuma, Aomori, Japan & LC223983 \\
\hline 23 & & & & Ij08-01 & Lake Kitaura, Ibaraki, Japan & LC223984 \\
\hline 24 & & & & Ij08-03 & Lake Kitaura, Ibaraki, Japan & LC223985 \\
\hline 25 & & & Inversiunio yanagawensis & Iy09-08 & Gion, Okayama, Japan & LC223986 \\
\hline 26 & & & & Iy09-10 & Gion, Okayama, Japan & LC223987 \\
\hline 27 & & & & Iy $43-01$ & Fukuoka, Japan & LC223988 \\
\hline 28 & & & & Iy $43-05 f$ & Fukuoka, Japan & LC223989 \\
\hline 29 & & & Lanceolaria grayii & Lg04-01SUTO & Hiroshima, Japan & LC223990 \\
\hline 30 & & & & Lg04-02SUTO & Hiroshima, Japan & LC223991 \\
\hline 31 & & & & Lg14-01SUTO & Gifu, Japan & LC223992 \\
\hline 32 & & & & Lg14-2f & Gifu, Japan & LC223993 \\
\hline 33 & & & & & Jiangxi, China & AF389408* \\
\hline 34 & & & Obovalis omiensis & Oo14-01m & Gifu, Japan & LC223994 \\
\hline 35 & & & & Oo16-01SUTO & Kyoto, Japan & LC223995 \\
\hline 36 & & & Pronodularia japanensis & Pj25-06 & Sakai, Yamagata, Japan & LC223996 \\
\hline 37 & & & & Pj14-02f & Gifu, Japan & LC223997 \\
\hline 38 & & & & Pj14-05f & Gifu, Japan & LC223998 \\
\hline 39 & & & & Pj08-01 & Lake Kitaura, Ibaraki, Japan & LC223999 \\
\hline
\end{tabular}




\section{Continued}

\begin{tabular}{|c|c|c|c|c|c|}
\hline 40 & & & Pj08-02 & Lake Kitaura, Ibaraki, Japan & LC224000 \\
\hline 41 & & & Pj04-01SUTO & Hiroshima, Japan & LC224001 \\
\hline 42 & & & Pj04-03SUTO & Hiroshima, Japan & LC224002 \\
\hline 43 & & & Pj-k & Sakurai, Nara, Japan & LC224019 \\
\hline 44 & & Inversidens brandti & Ib14-01f & Gifu, Japan & LC224003 \\
\hline 45 & & & Ib14-02f & Gifu, Japan & LC224004 \\
\hline 46 & & Hyriopsis schlegeli & Hs21-02f & Lake Anenuma, Aomori, Japan & LC224005 \\
\hline 47 & & & Hs21-05f & Lake Anenuma, Aomori, Japan & LC224006 \\
\hline 48 & & Cristaria plicata & Cp21-10f & Lake Anenuma, Aomori, Japan & LC224007 \\
\hline 49 & & & Cp21-11f & Lake Anenuma, Aomori, Japan & LC224008 \\
\hline 50 & & & Cp31-01fmg & Joetsu, Niigata, Japan & LC224009 \\
\hline 51 & & & YAMAKARA 1 & Lake Yamanakako, Yamanashi, Japan & LC223968 \\
\hline 52 & & & YAMAKARA 2 & Lake Yamanakako, Yamanashi, Japan & LC223969 \\
\hline 53 & & & YAMAKARA 5 & Lake Yamanakako, Yamanashi, Japan & LC223971 \\
\hline 54 & & & YAMAKARA 6 & Lake Yamanakako, Yamanashi, Japan & LC223970 \\
\hline 55 & & & & Zhejiang, China & FJ986302* \\
\hline 56 & & & & Jiangxi, China & AF389414* \\
\hline 57 & & Sinanodonta lauta & $\mathrm{fk} 168$ & Ishikawa, Japan & LC224010 \\
\hline 58 & & & KONZAISYU E & Lake Biwa, Shiga, Japan & LC223967 \\
\hline 59 & & & FUKUNUMA 22 & Minamisoma, Fukushima, Japan & LC223966 \\
\hline 60 & & Sinanodonta japonica & $\mathrm{fk} 20 \mathrm{f}$ & Kyoto, Japan & LC224011 \\
\hline 61 & & & $\mathrm{fk} 35 \mathrm{f}$ & Kushiro, Hokkaido, Japan & LC224012 \\
\hline 62 & & Sinanodonta calipygos & $\mathrm{fk} 221$ & Lake Biwa, Shiga, Japan & LC224013 \\
\hline 63 & & Sinanodonta ogurae & $\mathrm{fk} 156$ & Yodo River, Japan & LC224015 \\
\hline 64 & & Anemina arcaeformis & $\mathrm{fk} 63 \mathrm{f}$ & Kagawa, Japan & LC224014 \\
\hline 65 & & Pletholophus tenuis & Pt43-01 & Munakata, Fukuoka, Japan & LC224016 \\
\hline 66 & & & Pt43-02 & Munakata, Fukuoka, Japan & LC224017 \\
\hline 67 & & & Pt43-03 & Munakata, Fukuoka, Japan & LC224018 \\
\hline 68 & & Acuticosta ovata & & Jiangxi, China & $\mathrm{AF} 389412^{*}$ \\
\hline 69 & & Arconaia lanceolata & & Jiangxi, China & AF389409* \\
\hline 70 & & Cuneopsis pisciculus & & Jiangxi, China & AF389407 \\
\hline 71 & & Hyriopsis cumingii & & Jiangxi, China & AF389418* \\
\hline 72 & & Lamprotula leai & & Jiangxi, China & AF389415 \\
\hline 73 & & Lepidodesma languilati & & Jiangxi, China & AF389411* \\
\hline 74 & & Ptychorhynchus ptisteri & & Jiangxi, China & AF389416* \\
\hline 75 & & Schistodesmus lampreyanus & & Jiangxi, China & AF389410* \\
\hline 76 & & Sinanodonta woodiana & & Jiangxi, China & AF389413* \\
\hline 77 & & Solenaia oleivora & & Jiangxi, China & AF389417 \\
\hline 78 & Trigoniidae & Neotrigonia lamarckii & & data not available & KC429262* \\
\hline 79 & & Neotrigonia margaritacea & & data not available & DQ093489 \\
\hline 80 & & & & data not available & DQ280034 \\
\hline
\end{tabular}

*Obtained from the DDBJ. 
were purified using QIAquick ${ }^{\circledR}$ PCR Purification Kit (QIAGEN GmbH, Hilden, Germany). Sequence reactions were performed using GenomeLab ${ }^{\mathrm{TM}}$ DTCSQuick Start Kit (Beckman Coulter Inc., California, USA), and the same primers for PCR under the following conditions: 30 cycles of denaturation at $96^{\circ} \mathrm{C}$ for 20 sec, annealing at $50^{\circ} \mathrm{C}$ for $20 \mathrm{sec}$, and extension at $60^{\circ} \mathrm{C}$ for $4 \mathrm{~min}$. Direct sequencing of the double-stranded PCR products was performed using a $\mathrm{CEQ}^{\mathrm{TM}}$ 2000XL DNA Analysis system (Beckman Coulter Inc., California, USA) following the manufacturer's instructions. Sequences were deposited in the DNA Data Bank of Japan (DDBJ) under accession numbers LC223961-LC224020. The length of the sequences obtained ranged from $444 \mathrm{bp}$ in Hyriopsis schlegeli (Hs21-05f) to 525 bp in Margaritifera togakushiensis (Mt-k). We used seventeen $16 \mathrm{~S}$ rDNA sequences of Unionoida registered in the DDBJ (EU590914, GQ451850, GQ451851, AF389406, FJ986302, AF389414, AF389412, AF389409, AF389407, AF389418, AF389415, AF389408, AF389411, AF389416, AF389410, AF389413, AF389417), and we used Neotrigonia lamarckii (KC429262) and Neotrigonia margaritacea (DQ093489, DQ280034) sequences as the outgroup (Table 2).

\subsection{Phylogenetic Analysis}

DNA sequences of mitochondrial 16S rDNA were edited and aligned using DNASIS (Hitachi Software Engineering Co., Ltd., Tokyo, Japan) and MEGA 6.0 [21] and confirmed by visual inspection. No saturation was observed via analysis of nucleotide substitution patterns in mitochondrial 16S rDNA [9]. We used 347-bp sequences for tree construction including only Japanese unionoid species as the ingroup. On the other hand, we used 256-bp sequences for tree construction of East Asian unionoid species. Unfortunately, sequences for Chinese mussels deposited in the DDBJ [22] were shorter than those determined in this study. A neighbor-joining (NJ) tree was constructed using MEGA 6.0, and genetic distances were computed using Kimura's two-parameter model [23]. Tree reliability was evaluated by generating 1000 bootstrap replicates. Using PAUP $^{\star} 4.0$ beta10 [24], a majority-rule consensus maximum parsimony (MP) tree was constructed by conducting a heuristic search based on the 1000 bootstrap replicates with an unweighted transition/transversion ratio. A Bayesian (BI) tree was constructed using MrBayes version 3.2.6 [25] based on model evaluation done with MrModeltest 2.3 [26]. The best model for both trees was GTR + G. The Monte Carlo Markov chain (MCMC) length was $5 \times 10^{6}$ generations, and we sampled the chain every 100 generations. MCMC convergence was assessed by calculating the potential scale reduction factor, and the first $2.5 \times 10^{4}$ generations were discarded.

\section{Results}

Phylogenetic relationships of Japanese unionoids based on $347 \mathrm{bp}$ of the $16 \mathrm{~S}$ rRNA gene are shown in Figure 1. There were 183 variable sites and 176 informative sites. Topologies depicted by MP and Bayesian trees were essentially 


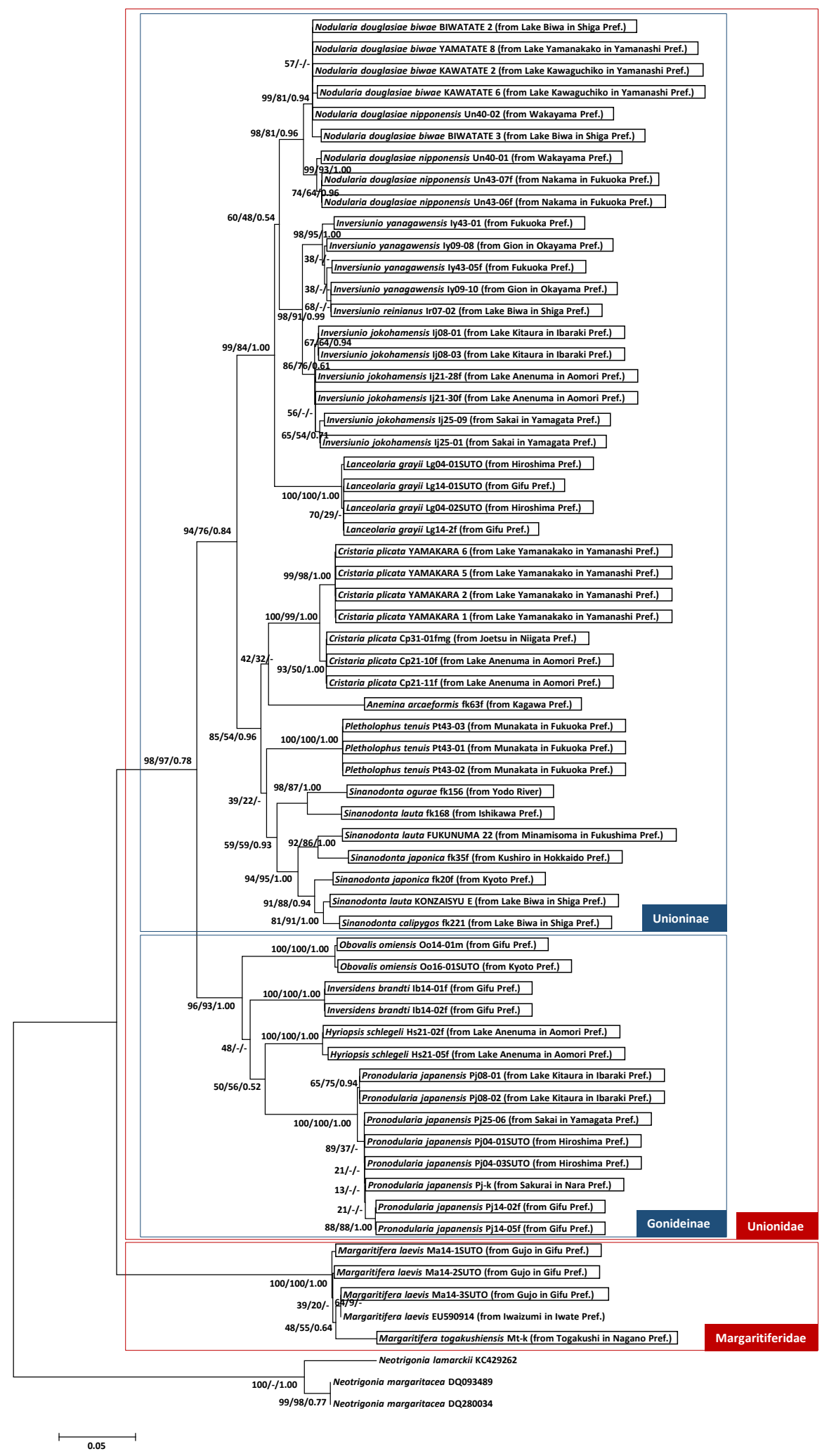

Figure 1. Japanese unionoid mussel NJ tree based on 347-bp 16S rDNA sequences from 64 specimens including three outgroup Neotrigonia specimens. The specimens, the sequences of which were newly determined in this study, are enclosed in squares. The scale bar indicates 0.05 substitutions per site. NJ (left) and MP (middle) bootstrap values and Bayesian posterior probabilities (right) are specified near the relevant nodes. Nodularia douglasiae was divided into two subspecies, $N$. d. biwae and N. d. nipponensis according to Kihira et al. [5]. The classifications depicted here are mainly based on Kondo [4]. 
identical to that of the $\mathrm{NJ}$ tree. Based on our analyses, Japanese unionoid mussels were divided into two well-supported clades (98/97/0.78 and 100/100/1.00, NJ/ MP/Bayesian, respectively) corresponding to two families, the Margaritiferidae and Unionidae. In the Unionidae, there were two well-supported clades (94/76/ 0.84 and 96/93/1.00) corresponding to the subfamilies Unioninae and Gonideinae. Most genera formed clades with high statistical supports. The only exception was the genus Sinanodonta, which formed a poorly supported clade (59/59/ 0.93). When two or more specimens were used, most species formed clades with robust statistical supports, even though the specimens were collected in distant localities. For example, Obovalis omiensis specimens were obtained from Gifu and Kyoto Prefectures, those of Lanceolaria grayii from Gifu and Hiroshima Prefectures, and those of Pronodularia japanensis from Ibaraki, Hiroshima, Nara, Gifu, and Yamagata Prefectures. However, Inversiunio jokohamensis formed a marginally supported clade (86/76/0.61). Inversiunio yanagawensis and Margaritifera laevis did not form their own species clades, and two species, Sinanodonta lauta and $S$. japonica, exhibited complicated relationships with $S$. ogurae and $S$. calipygos. The two subspecies described by Kihira et al. [5], Nodularia douglasiae biwae and $N$. d. nipponensis, did not form their own subspecies clades.

Phylogenetic relationships of East Asian unionoids based on $256 \mathrm{bp}$ of the $16 \mathrm{~S}$ rRNA gene are shown in Figure 2. There were 138 variable sites and 130 informative sites. Topologies depicted by MP and Bayesian trees were essentially identical to that of the NJ tree. Two robustly supported clades corresponding to the Margaritiferidae and Unionidae were recognized (100/100/1.00 and 100/99/ 1.00 , respectively). Most genera and species formed clades; however, Sinanodonta did not form its own clade. The Inversiunio clade was well supported in the Japanese unionoid tree (Figure 1), but was only marginally supported in the East Asian unionoid tree (Figure 2) likely due to the shorter sequences used to make the latter tree. On the other hand, Margaritifera laevis was paraphyletic in the Japanese unionoid tree (Figure 1), but it formed a clade in the East Asian unionoid tree (Figure 2).

\section{Discussion}

Japanese unionoid mussels were basally divided into two clades corresponding to the two families described by Kondo [4] who showed that the Margaritiferidae had interlamellar gill junctions arranged in diagonal rows, while the Unionidae had interlamellar gill junctions combined into vertical septa. Rosenberg et al. [27] presented preliminarily the molecular phylogeny of invertebrate animals, including the Unionoida, by analyzing the D6 region (about 150-bp) of the nuclear $28 \mathrm{~S}$ rRNA gene. They showed that margaritiferid species could be distinguished from other unionoid species, which supported our results.

Kondo [4] reported that there were two subfamilies, the Unioninae and Gonideinae, in the family Unionidae. He regarded mussels having subtriangular and hooked glochidia as Unioninae and those having essentially semi-elliptical 


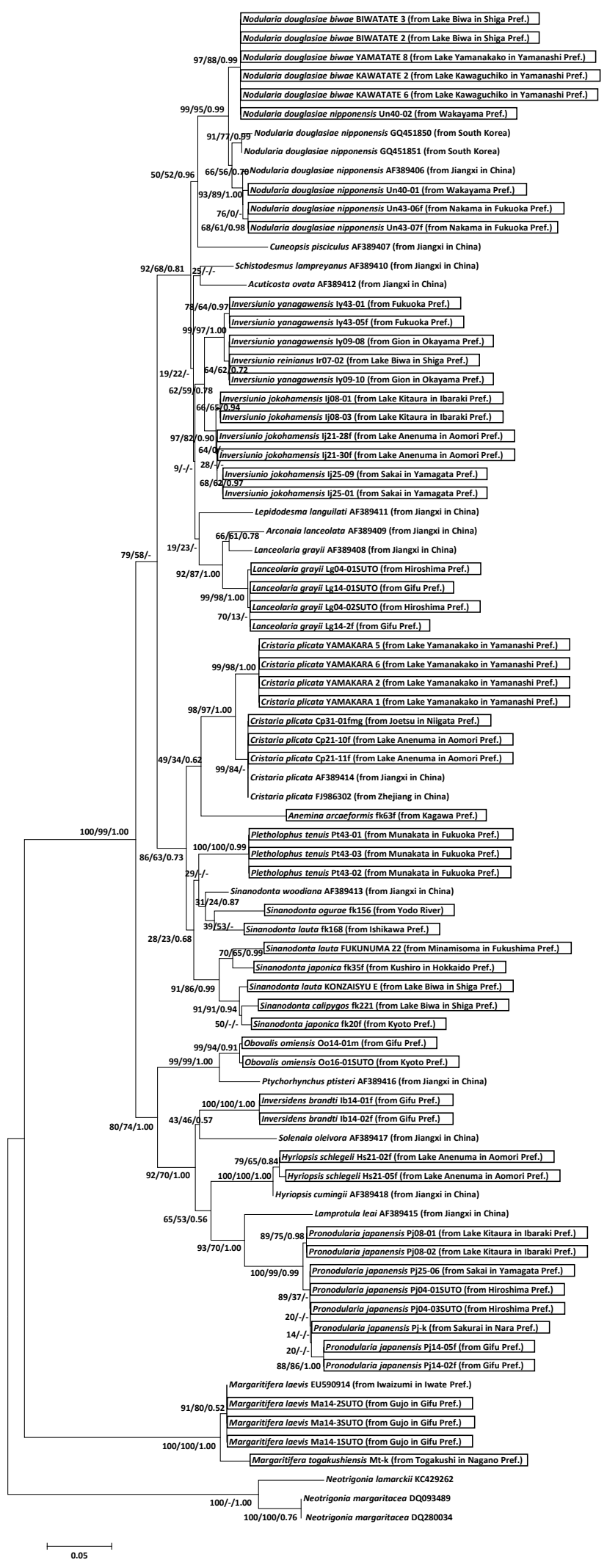

Figure 2. East Asian unionoid mussel NJ tree based on 256-bp 16S rDNA sequences from 80 specimens including three outgroup Neotrigonia specimens. The specimens, the sequences of which were newly determined in this study, are enclosed in squares. The scale bar indicates 0.05 substitutions per site. NJ (left) and MP (middle) bootstrap values and Bayesian posterior probabilities (right) are specified near the relevant nodes. 
and unhooked glochidia as Gonideinae. Our results supported Kondo's subfamily classification. Kondo [4] further classified unionoid mussels into 12 genera and 18 species, mainly based on their shell morphology. In this study, most genera formed well supported clades, although the genus Sinanodonta was poorly supported. Most species also formed well supported clades, but one species formed a marginally supported clade or some did not form clades at all. Takeuchi et al. [12] showed that a phylogenetic tree based on mitochondrial COI sequences distinguished M. laevis from M. togakushiensis. Our results supported their results in the East Asian unionoid tree (Figure 2), but not in the Japanese unionoid tree (Figure 1). Of the three species of Inversiunio, I. jokohamensis was marginally supported and $I$. yanagawensis was paraphyletic, but $I$. yanagawensis and I. reinianus formed a clade together. Genetic distances between $I$. yanagawensis and $I$. reinianus (0.00581 in Table 3 and 0.00394 in Table 4) were as low as the intraspecific genetic distances within I. jokohamensis (0.00405 in Table 3 and 0.00419 in Table 4). Therefore, in this study, I. yanagawensis could not be genetically well-distinguished from I. reinianus. Complicated relationships between Sinanodonta species seem to be derived from large morphological variation within the genus, which sometimes confuses species identification [5] [28]. To obtain more robust phylogenetic relationships of those species, we need to collect and analyze more specimens and use another gene such as the mitochondrial cytochrome oxidase subunit I (COI) gene for molecular barcording.

Kihira et al. [5] recognized Lanceolaria oxyrhyncha as a valid species different from L. grayii, which is widely distributed in Japan. However, Kondo [3] claimed that $L$. oxyrhyncha could not be separated morphologically from $L$. grayii, and Shirai [29] showed that L. oxyrhyncha was not genetically distinct from L. grayii. Kihira et al. [5] recognized Cristaria plicata clessini as a valid subspecies. However, Kondo [3] showed that C. p. clessini seems to be a lacustrine type of C. plicata and considered it doubtful that $C$. p. clessini is a subspecies. Hence, we did not use L. oxyrhyncha or C. p. clessini in this study. Nodularia douglasiae was also problematic. Kihira et al. [5] established two subspecies, $N$. d. biwae and $N$. d. nipponensis, and Kondo [30] regarded the individuals with milky-white glochidia as $N$. d. biwae and the others with buff glochidia as $N$. d. nipponensis. Later, Kondo [4] resolved that glochidium colors did not seem to be sufficiently diagnostic to identify the subspecies because there was substantial variation in color as is also often the case with Inversidens brandti and Lanceolaria grayii. We showed in this study that one specimen of $N$. d. nipponensis (Un40-02) was more closely related to specimens of $N$. $d$. biwae than to the other specimens of N. d. nipponensis. Shirai [29] showed, based on mitochondrial DNA (COI + II), that Nodularia douglasiae is divided into two clades (east and west), but each subspecies did not form its own clade. Taken together, these results suggest that $N$. d. biwae and $N$. d. nipponensis are not valid as subspecies.

The phylogenetic relationships obtained in this study essentially supported the systematics proposed by Kondo [4] that are primarily based on morphological and larval traits. Never before have any published studies comprehensively in- 


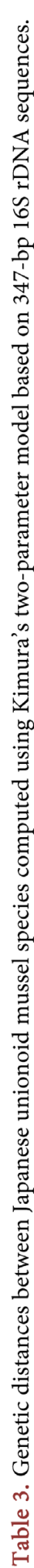

(dnoxs̊ำก)

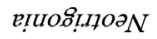

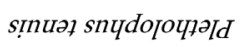

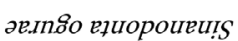

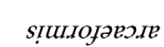

витшгин

so8̊dIItes

вұนopouru!s

exinoder

eұuopoueu!s

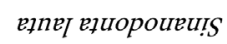

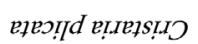

!!วठ̊ว

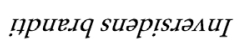

sIsuautde!

extermpouo: ${ }_{d}$

sIsนว!นо S!IPAOqO

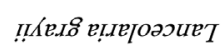

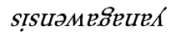

OIUnIS.T2AUII

sІsцаштечоуо!

o!UnIs.дaมUI

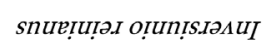

sІรиәнодdIU

aetselosnop e!lielnpoN

วeм!q äISElonop

P!I.IIIRPoN

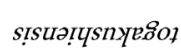

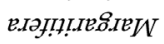

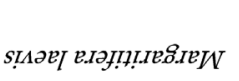

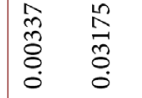

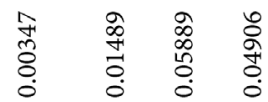

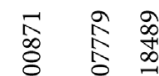

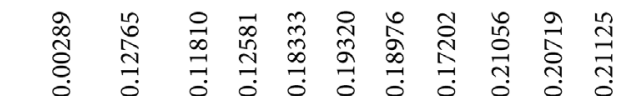

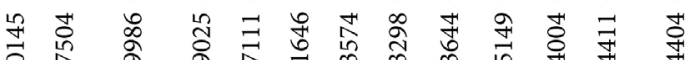

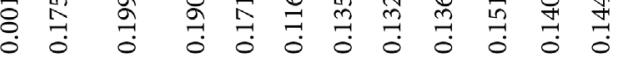

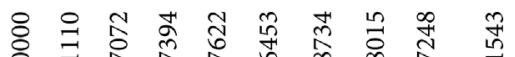

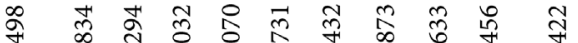

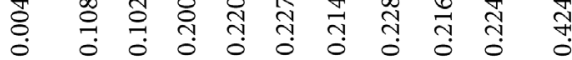

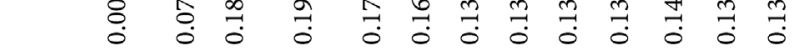

\%

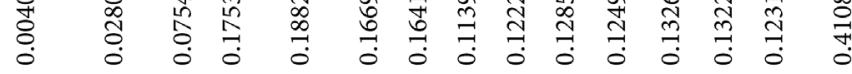

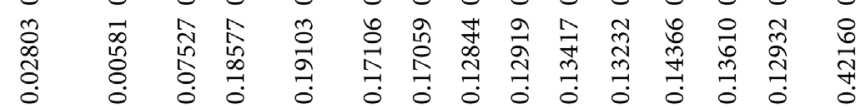

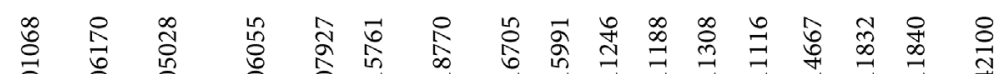

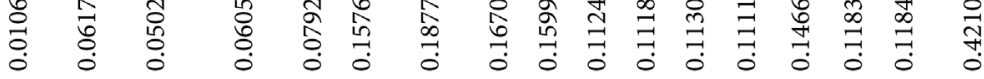

(a)

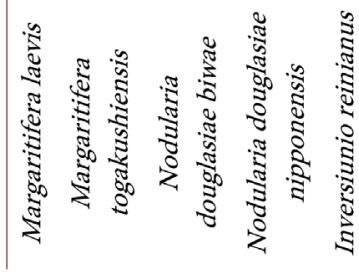

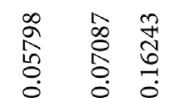

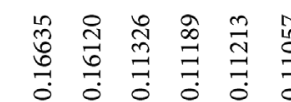

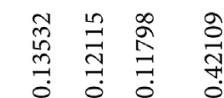

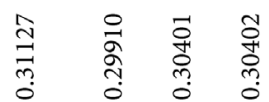

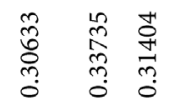

总

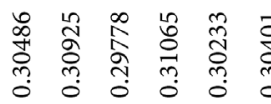

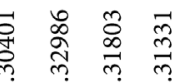

$\stackrel{\vec{m}}{m} \stackrel{m}{m}$

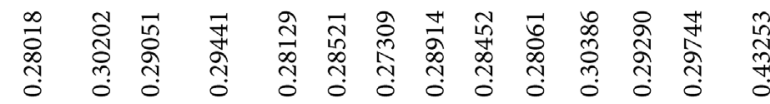

:
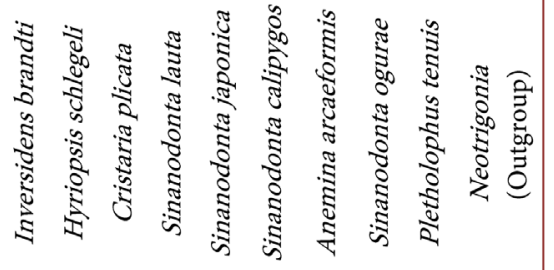


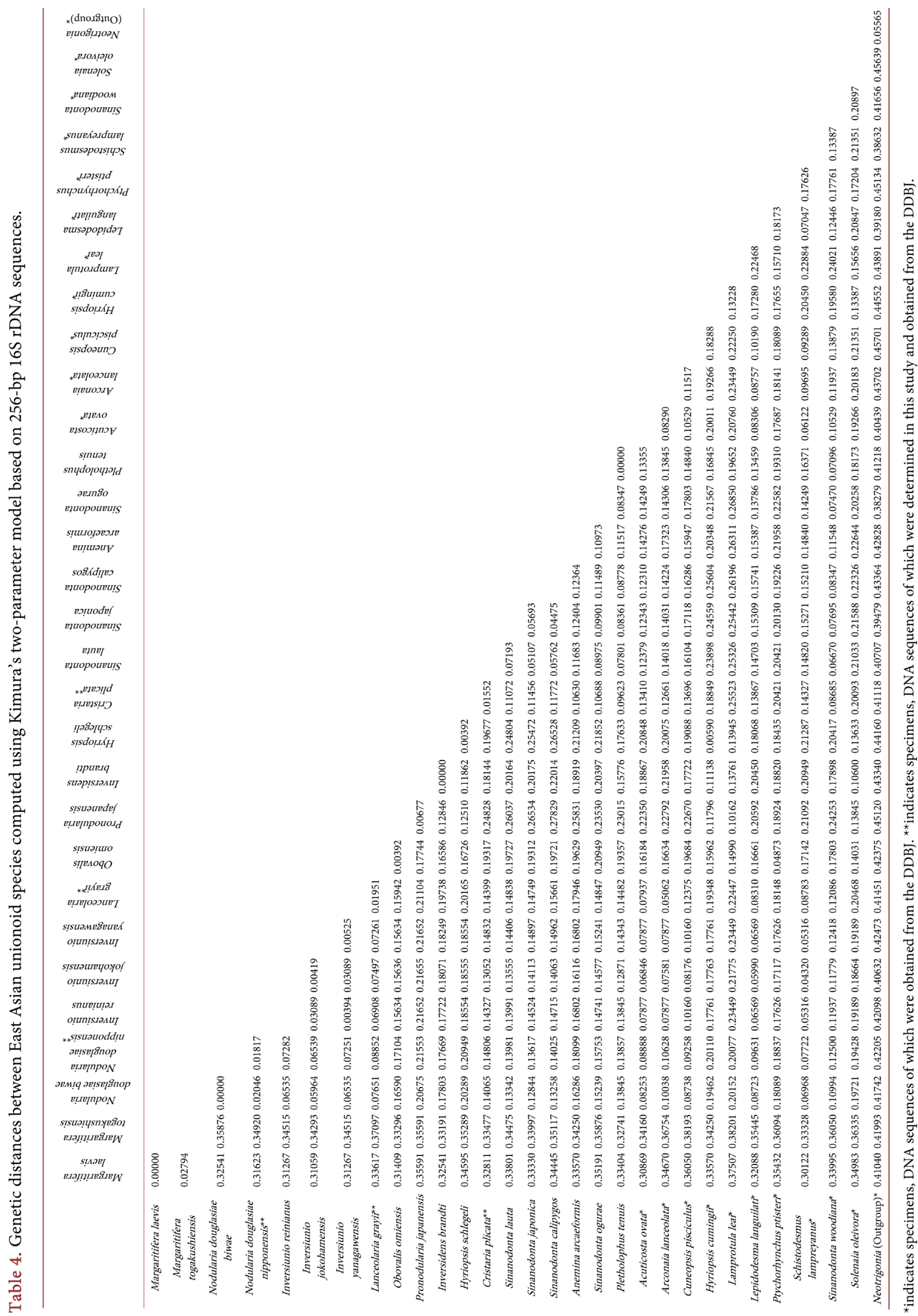


vestigated the molecular phylogeny of Japanese unionoid taxa; thus, this study is the first to do so and the first to evaluate the current classification of Japanese Unionoida. Since our genetic data and Kondo's morphological data present consistent phylogenetic relationships, we conclude that mitochondrial $16 \mathrm{~S}$ rDNA is useful for assessing relationships among invertebrate animals, including unionoid mussels, as has been described before [9] [31].

Since Japanese unionoid mussels seem to have evolutionary origins and common ancestors in the East Asian continent, we investigated the phylogenetic relationships between Japanese and East Asian unionoids. Huang et al. [22] investigated the phylogenetic relationships of Chinese unionoids using 16S rDNA sequences and presented similar results to ours despite the addition of Japanese unionoids in our study, confirming reliability of our sequences. However, they insisted that Chinese unionids, formerly classified into two subfamilies, should be divided into three: the Unioninae comprising seven species (Nodularia douglasiae nipponensis, Cuneopsis pisciculus, Lepidodesma languilati, Schistodesmus lampreyanus, Arconaia lanceolate, Lanceolaria grayii, and Acuticosta ovata), the Anodontinae comprising two species (Sinanodonta woodiana and Cristaria plicata), and the Ambleminae comprising four species (Ptychorhynchus ptisteri, Hyriopsis cumingii, Lamprotula leai, and Solenaia oleivora). The subfamily Ambleminae corresponded to the subfamily Gonideinae by Kondo, and the subfamilies Unioninae and Anodontinae together corresponded to the subfamily Unioninae by Kondo [4].

Recently, Lopes-Lima et al. [11] analyzed a combined dataset of mitochondrial COI + nuclear 28S rDNA sequences and classified global unionoids. According to their classification, the mussels in Kondo's Unioninae were separated into two subfamilies, the Unioninae and Anodontinae. In this study, mussels included in Kondo's Unioninae were genetically divided into two clades. However, the clades were not assigned to the two subfamilies of Lopes-Lima et al. because the position of the genus Lanceolaria was inconsistent between their study and ours.

Many unionoid mussels are facing extinction [13] [14] [15] [16], and freshwater mussels have close associations with other freshwater organisms thus offering important information for identifying hotspots where biodiversity is high but is being destroyed due to human activities [32]. However, it is only when classification is well established and genetic diversity has been sufficiently investigated that this important information can be obtained. Therefore, the precise classification and evaluation of genetic diversity is indispensable for conserving Japanese unionoid mussels [33] [34]. The present study provides useful information that can be used for the conservation of endangered mussels and for promoting their protection.

This study is a first report presenting phylogenetic relationships of all Japanese unionoid species. We summarized our important findings concerning the phylogeny and classification as follows: (1) the order Unionoida formed a clade, (2) unionoid mussels were divided into two clades corresponding to the two families, Margaritiferidae and Unionidae, (3) unionid mussels were divided into 
two clades corresponding to the two subfamilies, Unioninae and Gonideinae, (4) unionine mussels were further divided into two clades, (5) most genera and species are monophyletic, (6) the phylogenetic relationships obtained in this study fundamentally supported the systematics of Japanese unionoids proposed by Kondo [4] that are based on morphological and larval traits. Some uncertainties were detected among the phylogenetic relationships of Japanese unionoid mussels, although our study demonstrated that $16 \mathrm{~S}$ rDNA was useful for deducing these relationships. Therefore, further studies are needed using more specimens obtained from different localities and using other genes in addition to the $16 \mathrm{~S}$ rDNA gene. More refined morphological and physiological studies are also necessary. Sequencing of the COI gene is in progress to obtain more robust phylogenetic relationships and to enable molecular barcoding of the species, and we have been obtaining promising data fundamentally consistent with those presented in this study.

\section{Acknowledgements}

We express our sincere appreciation to Dr. Youki Fukasawa for his technical support. We wish to thank Mr. Osamu Inaba for his assistance in collecting unionoid specimens.

\section{References}

[1] Bogan, A.E. (2008) Global Diversity of Freshwater Mussels (Mollusca, Bivalvia) in Freshwater. Hydrobiologia, 595, 139-147.

https://doi.org/10.1007/s10750-007-9011-7

[2] Graf, D.L. and Cummings, K.S. (2007) Review of the Systematics and Global Diversity of Freshwater Mussel Species (Bivalvia: Unionoida). Journal of Molluscan Studies, 73, 291-314. https://doi.org/10.1093/mollus/eym029

[3] Kondo, T. (2008) Monograph of Unionoida in Japan (Mollusca: Bivalvia). Special Publication of the Malacological Society of Japan, No. 3, 69 p.

[4] Kondo, T. (2015) Catalogue of Japanese Unionid Shells in Takaki Kondo's Collection. Osaka Kyoiku University, 58 p. (In Japanese)

[5] Kihira, H., Matsuda, M. and Uchiyama, R. (2003) Freshwater Mollusks of Japan 1. Freshwater Mollusks in Lake Biwa and Yodo River. Pisces, Tokyo, 160 p. (In Japanese)

[6] Heard, W.H. and Guckert, R.H. (1970) A Re-Evaluation of the Recent Unionacea (Pelecypoda) of North America. Malacologia, 10, 333-355.

[7] Graf, D.L. and Foighil, D.Ó. (2000) The Evolution of Brooding Characters among the Freshwater Pearly Mussels (Bivalvia: Unionoidea) of North America. Journal of Molluscan Studies, 66, 157-170. https://doi.org/10.1093/mollus/66.2.157

[8] Hoeh, W.R., Bogan, A.E. and Heard, W.H. (2001) A Phylogenetic Perspective on the Evolution of Morphological and Reproductive Characteristics in the Unionoida. In: Bauer, G. and Wächtler, K., Eds., Ecology and Evolution of the Freshwater Mussels Unionoida, Springer, Berlin, Heidelberg, 257-280.

https://doi.org/10.1007/978-3-642-56869-5_14

[9] Lydeard, C., Mulvey, M. and Davis, G.M. (1996) Molecular Systematics and Evolution of Reproductive Traits of North American Freshwater Unionacean Mussels (Mollusca: Bivalvia) as Inferred from 16S rRNA Gene Sequences. Philosophical 
Transactions of the Royal Society of London B: Biological Sciences, 351, 1593-1603. https://doi.org/10.1098/rstb.1996.0143

[10] Mulvey, M., Lydeard, C., Pyer, D.L., Hicks, K.M., Brim-Box, J., Williams, J.D., et al. (1997) Conservation Genetics of North American Freshwater Mussels Amblema and Megalonaias. Conservation Biology, 11, 868-878. https://doi.org/10.1046/j.1523-1739.1997.95487.x

[11] Lopes-Lima, M., Froufe, E., Ghamizi, M., Mock, K.E., Kebapçı, Ü., Klishko, O., et al. (2017) Phylogeny of the Most Species-Rich Freshwater Bivalve Family (Bivalvia: Unionida: Unionidae): Defining Modern Subfamilies and Tribes. Molecular Phylogenetics and Evolution, 106, 174-191. http://doi.org/10.1016/j.ympev.2016.08.021

[12] Takeuchi, M., Okada, A. and Kakino, W. (2015) Phylogenetic Relationships of Two Freshwater Pearl Mussels, Margaritifera laevis (Haas, 1910) and Margaritifera togakushiensis Kondo and Kobayashi, 2005 (Bivalvia: Margaritiferidae), in the Japanese Archipelago. Molluscan Research, 35, 218-226. https://doi.org/10.1080/13235818.2015.1053165

[13] Ministry of the Environment in Japan (2015) Red List of Shellfishes. (In Japanese) http://www.env.go.jp/press/files/jp/28064.pdf

[14] Geist, J. (2010) Strategies for the Conservation of Endangered Freshwater Pearl Mussels (Margaritifera margaritifera L.): A Synthesis of Conservation Genetics and Ecology. Hydrobiologia, 644, 69-88. https://doi.org/10.1007/s10750-010-0190-2

[15] Strayer, D.L. (2006) Challenges for Freshwater Invertebrate Conservation. Freshwater Science, 25, 271-287. https://doi.org/10.1899/0887-3593(2006)25[271:CFFIC]2.0.CO;2

[16] Strayer, D.L. and Dudgeon, D. (2010) Freshwater Biodiversity Conservation: Recent Progress and Future Challenges. Freshwater Science, 29, 344-358. https://doi.org/10.1899/08-171.1

[17] Takeuchi, M. (2013) New Localities of the Freshwater Mussel Margaritifera togakushiensis in Aomori Prefecture, with Special Reference to the Present Conditions. Journal of the Natural History of Aomori, 18, 17-23. (In Japanese with English Abstract)

[18] Negishi, J.N., Kayaba, Y., Tsukahara, K. and Miwa, Y. (2008) Unionoid Mussels as Imperiled Indicator Organisms: Habitat Degradation Processes and Restoration Approaches. Ecology and Civil Engineering, 11, 195-211. (In Japanese with English Abstract) https://doi.org/10.3825/ece.11.195

[19] Shirai, A., Kondo, T. and Kajita, T. (2010) Molecular Markers Reveal Genetic Contamination of Endangered Freshwater Pearl Mussels in Pearl Culture Farms in Japan. Venus, 68, 151-163.

[20] Hoeh, W.R., Stewart, D.T., Saavedra, C., Sutherland, B.W. and Zouros, E. (1997) Phylogenetic Evidence for Role-Reversals of Gender-Associated Mitochondrial DNA in Mytilus (Bivalvia: Mytilidae). Molecular Biology and Evolution, 14, 959 967. https://doi.org/10.1093/oxfordjournals.molbev.a025839

[21] Tamura, K., Stecher, G., Peterson, D., Filipski, A. and Kumar, S. (2013) MEGA6: Molecular Evolutionary Genetics Analysis Version 6.0. Molecular Biology and Evolution, 30, 2725-2729. https://doi.org/10.1093/molbev/mst197

[22] Huang, Y., Liu, H., Wu, X. and Ouyang, S. (2002) Testing the Relationships of Chinese Freshwater Unionidae (Bivalvia) Based on Analysis of Partial Mitochondrial $16 \mathrm{~S}$ rRNA Sequences. Journal of Molluscan Studies, 68, 359-363. https://doi.org/10.1093/mollus/68.4.359

[23] Kimura, M. (1980) A Simple Method for Estimating Evolutionary Rates of Base Substitutions through Comparative Studies of Nucleotide Sequences. Journal of 
Molecular Evolution, 16, 111-120. https://doi.org/10.1007/BF01731581

[24] Swofford, D.L. (2002) PAUP* Version 4.0 b10. Phylogenetic Analysis Using Parsimony ( ${ }^{*}$ and Other Methods). Sinauer, Sunderland.

[25] Ronquist, F., Teslenko, M., van der Mark, P., Ayres, D.L., Darling, A., Höhna, S., Larget, B., et al. (2012) MrBayes 3.2: Efficient Bayesian Phylogenetic Inference and Model Choice across a Large Model Space. Systematic Biology, 61, 539-542. https://doi.org/10.1093/sysbio/sys029

[26] Posada, D. and Buckley, T.R. (2004) Model Selection and Model Averaging in Phylogenetics: Advantages of Akaike Information Criterion and Bayesian Approaches over Likelihood Ratio Tests. Systematic Biology, 53, 793-808. https://doi.org/10.1080/10635150490522304

[27] Rosenberg, G., Kuncio, G.S., Davis, G.M. and Harasewyeh, M.G. (1994) Preliminary Ribosomal RNA Phylogeny of Gastropod and Unionoidean Bivalve Molluscs. The Nautilus, Suppl. 2, 111-121.

[28] Kondo, T., Tabe, M. and Fukuhara, S. (2011) Separating Anodonta lauta and Anodonta japonica by Shell Shape. Chiribotan, 41, 84-88. (In Japanese)

[29] Shirai, A. (2009) Molecular Phylogenetic Study of Freshwater Mussels (Unionoida) in Japan. PhD Dissertation, Chiba University, Chiba, Japan. (In Japanese)

[30] Kondo, T. (1997) Taxonomic Position and Distribution of Unio biwae (Bivalvia: Unionidae). Japanese Journal of Malacology, 56, 41-47.

[31] Turner, T.F., Trexler, J.C., Harris, J.L. and Haynes, J.L. (2000) Nested Cladistic Analysis Indicates Population Fragmentation Shapes Genetic Diversity in a Freshwater Mussel. Genetics, 154, 777-785.

[32] Graf, D.L. and Cummings, K.S. (2011) Freshwater Mussel (Mollusca: Bivalvia: Unionoida) Richness and Endemism in the Ecoregions of Africa and Madagascar Based on Comprehensive Museum Sampling. Hydrobiologia, 678, 17-36. https://doi.org/10.1007/s10750-011-0810-5

[33] Darwall, W.R.T. and Vié, J.C. (2005) Identifying Important Sites for Conservation of Freshwater Biodiversity: Extending the Species-Based Approach. Fisheries Management and Ecology, 12, 287-293. https://doi.org/10.1111/j.1365-2400.2005.00449.x

[34] Faith, D.P. (1992) Conservation Evaluation and Phylogenetic Diversity. Biological Conservation, 61, 1-10. https://doi.org/10.1016/0006-3207(92)91201-3

\section{Scientific Research Publishing}

\section{Submit or recommend next manuscript to SCIRP and we will provide best} service for you:

Accepting pre-submission inquiries through Email, Facebook, LinkedIn, Twitter, etc. A wide selection of journals (inclusive of 9 subjects, more than 200 journals)

Providing 24-hour high-quality service

User-friendly online submission system

Fair and swift peer-review system

Efficient typesetting and proofreading procedure

Display of the result of downloads and visits, as well as the number of cited articles

Maximum dissemination of your research work

Submit your manuscript at: http://papersubmission.scirp.org/

Or contact jwarp@scirp.org 